\title{
O CORPO EM OUTDOORS DA CIDADE DE NATAL/RN ${ }^{1}$
}

Recebido em: 01/10/2015

Aceito em: 15/05/2016

\author{
Iasmim de Pontes Araújo \\ Marcel Alves Franco \\ Maria Isabel Brandão de Souza Mendes \\ Universidade Federal do Rio Grande do Norte \\ Natal - RN - Brasil
}

RESUMO: Nesta pesquisa, realizamos um estudo documental a partir de seis outdoors da cidade de Natal/RN e, a partir da análise de conteúdo, nosso objetivo foi identificar o ideal de corpo divulgado em outdoors da cidade de Natal. Como critério, as imagens deveriam estar relacionadas aos cuidados com o corpo e com a saúde. Foi a partir de propagandas de suplementos alimentares, academias, estúdios de pilates e clínicas de nutrição que problematizamos a construção e divulgação de um ideal de corpo, de musculatura definida, sedutor, feliz e magro, na tentativa de apontar algumas implicações para a Educação Física, no tocante à saúde, ao consumo, ao lazer, entre outras temáticas. Concluímos ser imprescindível os profissionais de Educação Física refletirem sobre a proliferação do culto ao corpo em nossa sociedade, incluindo sobre o uso de imagens do corpo nos outdoors.

PALAVRAS CHAVE: Corpo Humano. Propaganda. Educação Física.

\section{THE BODY IN OUTDOORS AT THE CITY OF NATAL /RN}

ABSTRACT: In this research, we performed a documentary study from six outdoors in the city of Natal/RN and, using the content analysis, our goal was to identify the body ideal disclosed on outdoors at the city of Natal. As a criterion, the images should be related to body care and with the health. There was from the publicity of alimental supplements, gyms, studium of pilates and nutricion clinics that we discussed the construction and the spreading of one body ideal, with defined muscles, seductor, happy and thin, trying to point to some implications for Physical Education, about health, consuming, leisure, and other issues. We concluded that it is imperative to Physical Education professionals to reflect about the spread of the cult of the body in our society, including about the using of body images on the outdoors.

KEYWORDS: Human Body. Publicity. Physical Education.

\footnotetext{
${ }^{1}$ Agradecemos ao Conselho Nacional de Desenvolvimento Científico e Tecnológico (CNPq) pelo apoio financeiro com uma bolsa de iniciação científica e à Fundação de Apoio à Pesquisa do Rio Grande do Norte (FAPERN) e à Coordenação de Aperfeiçoamento Pessoal de Nível Superior (CAPES) pelo apoio financeiro com uma bolsa de mestrado, para o fomento da pesquisa.
} 


\section{Introdução}

O corpo é o que somos. Ele fala através dos movimentos e se comunica com outros corpos. Além disso, nosso corpo é educado por todos os lugares que convivemos. Como destaca Soares (2001, p. 110): “os corpos são educados por toda realidade que os circunda, por todas as coisas com as quais convivem, pelas relações que se estabelecem em espaços definidos e delimitados por atos de conhecimento".

Assim, ao refletirmos sobre os usos do corpo na contemporaneidade, fizemos alguns questionamentos: como o corpo tem sido compreendido hoje em dia? Com que práticas relacionadas ao uso do corpo temos nos deparado na atualidade? Segundo Castro (2003), na sociedade atual existe um culto ao corpo que está associado ao consumo.

Werneck (1998) aponta que a partir das estratégias de mercado (marketing), são elaboradas necessidades de consumo. Esta autora discute a imposição de novos padrões de vida e as consequências deste processo nas dimensões do trabalho e do lazer na sociedade.

Lacerda e Isayama (2009) trazem em seu estudo, proposições acerca de uma relação existente entre o consumo e o lazer que corrobora com a ideia de o consumo influenciar a construção de identidade, pois parte-se do princípio do indivíduo intencionar ser parte de determinado grupo social e para isso deveria consumir das mesmas coisas que este coletivo.

Em Leitzke, Baptista e Silva (2014, p. 184), identificamos que existem instâncias, como "a escola, a mídia, as relações familiares, religiosas, trabalhistas", que influenciam diretamente a constituição do sujeito e mecanismos sociais que diminuem a chance de questionamento sobre as proposições de ordem econômico-social capitalista, juntamente com seus preceitos e lógicas consumistas. Os autores referem-se à Indústria Cultural:

A "indústria cultural" pode ser entendida como um instrumento de pressão da sociedade sobre o individuo através da utilização de elementos 
culturais que se tomam acessíveis pelo cinema, pela televisão e por outros meios de comunicação de massa. Esses são utilizados como formas de cooptarem os indivíduos para uma atuação de acordo com os interesses e as necessidades do modo de produção fazendo a lógica industrial prevalecer (BAPTISTA apud LEITZKE; BAPTISTA; SILVA, 2014, p. $185)$.

Neste sentido, entendemos a indústria cultural como responsável pela produção das propagandas, como os diversos tipos de outdoors ${ }^{2}$. Este recurso é utilizado por empresas para fim de divulgação de seus produtos e para sugerir seu consumo, por parte da sociedade.

Em nossa pesquisa, nos inquietamos com o uso da imagem do corpo em outdoors na cidade de Natal/RN. Devido à localização em pontos de alta movimentação na cidade, pensamos que algumas das formas de consumo pode ser facilitado pelo fluxo do trânsito, por sua posição e tamanho oferecer maior visibilidade tanto para pedestres como para motoristas. De uma forma mais direta, pela oferta divulgada estabelecer também seu público alvo, que variam de frequentadores de academias - independente de ser em razão de práticas específicas como a musculação, a ginástica, a reabilitação, ou até mesmo por lazer -, de praticantes de Pilates, de possíveis consumidores de suplementação alimentar, entre outros exemplos.

Neste sentido, faz-se necessário repensarmos também nesta relação entre lazer e consumo. Segundo Lacerda e Isayama (2009), o lazer se torna um âmbito de investimento sob olhos da Indústria Cultural. Para os autores, esta indústria aproveita-se do consumo para lançar uma infinidade de produtos de lazer e para favorecer seu reconhecimento. Entretanto, "em termo geral, uma pessoa pode ter um lazer significativo e de qualidade

\footnotetext{
${ }^{2}$ É considerado outdoor, nesta pesquisa, as propagandas veiculadas através de imagens pela cidade de forma pública. Além disso, ressaltamos que todas as fotos de outdoors apresentadas nesta pesquisa foram realizadas por Rivaldo José Fernandes dos Santos Júnior durante a participação no projeto de Iniciação Científica no curso de Educação Física na Universidade Federal do Rio Grande do Norte, no período de novembro, de 2014, a fevereiro, de 2015 .
} 
quando consome, até mesmo quando este ato é permeado pelos preceitos da Indústria Cultural" (LACERDA; ISAYAMA, 2009, p. 11).

Acreditamos que este tipo de investigação com outdoors se justifica por haver possibilidade de evidenciar uma leitura que não se remete à saúde, mas ao consumo da imagem de um corpo que não é o nosso. Nos termos propostos por Baudrillard (2008, p. 168), o corpo é meio de aquisição de status sociais: "Na panóplia do consumo, o mais belo, precioso e resplandecente de todos os objetos [...] é o corpo".

Neste sentido, a sociedade impõe um modelo de corpo, o qual é passível de ser instituído como referência de o corpo ideal. De acordo com Baudrillard (2008, p. 172), “o corpo como patrimônio; manipula-se como um dos múltiplos significantes de estatuto social".

Na perspectiva de Bruhns (2009), a ênfase na racionalidade, resultante de um processo histórico, privilegiou a aparência do corpo. A autora aponta que o corpo seria avaliado pelos critérios de delineamento muscular, suas formas e a constituição ósteoarticular, que desprezam parâmetros não racionais, tais como desejo, emoção e sentimento.

Bruhns (2009, p. 13) apresenta, em seu estudo, o corpo emergente, “descentrado, não-limitado, sistema recebendo signos, aberto para ser (re) construído através de um jogo de forças", e a partir dele levanta a necessidade em questionarmos "o que um corpo faz?".

De forma metafórica, o corpo emergente é compreendido como recurso para o que a autora denominou de crise do lazer moderno, "pois traduz inquietações, anseios, mobilidades, apontando para a necessidade de melhor compreensão da questão bem como para a necessidade de novos enfoques" (BRUHNS, 2009, p. 13).

Por sua vez, os estudos de Nóbrega (2001; 2010), demonstram pontos de ligação entre o uso da imagem do corpo, na perspectiva do consumo, o agenciamento do corpo e a 
noção de corpo-outdoor. Acerca do agenciamento, a autora aborda os usos do corpo na sociedade contemporânea e considera, em decorrência deste conceito, que a convivência com a tecnologia da transformação corporal e a produção de subjetividades se dará, por vezes, de forma conflituosa.

\begin{abstract}
O movimento em torno das imagens de corpo refere-se diretamente à questão do valor. Nesse contexto, a mídia assume uma função estratégica de divulgar certo modelo de vida, de padrões e de comportamentos. Especialmente em relação ao corpo, o discurso da mídia carece de uma análise científica e de reflexão sobre o estatuto do corpo na contemporaneidade, uma vez que, por meio de sofisticados recursos técnicos e tecnológicos, a percepção é mutilada. O movimento veloz da mídia em divulgar imagens e modelos de corpo produz uma corrida alucinada aos métodos e técnicas de modificação do corpo para adaptar-se à moda. $\mathrm{O}$ destino do corpo torna-se prótese, seja por cirurgia ou imagem (NÓBREGA, 2010, p. 26).
\end{abstract}

Neste aspecto, podemos perceber uma abertura para a configuração dos valores sociais acerca do corpo, os quais Nóbrega $(2001 ; 2010)$ exemplifica através das possíveis relações de maneira temática entre o corpo e a Religião, a Filosofia, a Ciência, a Educação e a Arte: "Ao corpo se atribuem valores como corpo-objeto, corpo-mercadoria, corpopecado, corpo-sujeito, corpo-prótese, enfim, cada época constrói o seu próprio modelo de corpo, embora sempre esteja em contato com os modelos anteriores" (NÓBREGA, 2001, p. $1)$.

Assim, algo que facilmente percebemos nas ruas de Natal é a utilização, em diversas maneiras, da imagem do corpo para fins lucrativos. Propagandas que usam a imagem do corpo, literalmente, como outdoor para anunciar algum produto.

$\mathrm{Na}$ contemporaneidade é possível observar em diferentes momentos e lugares a associação entre saúde e um padrão específico de estética corporal (MENDES, 2009). Portanto, as propagandas perpassam o ideário social. O corpo é esculpido de forma a 
estimular uma necessidade de cuidado excessivo por parte do seu público. O que nos remete à noção de corpo-outdoor:

\begin{abstract}
Uma nova cultura do consumo se estabelece a partir da imagem do corpo, sexualmente disponível e associado ao hedonismo, ao lazer e à exibição, enfatizando a importância da aparência e do visual. Essas imagens de corpo são divulgadas pelos meios de comunicação de massa e mídia eletrônica, exigindo toda uma rotina de exercícios, dietas, cosméticos, terapias, entre outras preocupações com a imagem e a auto-imagem, uma exposição sem limites do corpo (corpo-outdoor) (NÓBREGA, 2001, p. 2).
\end{abstract}

Assim, quando nos dirigimos para estudos sobre o culto ao corpo, identificamos alguns estudos sobre essa temática que são abordados de diversas maneiras. A saber, como critério de identificação, buscamos o culto ao corpo em títulos e resumos de estudos já publicados. Foram encontrados nove artigos em certos periódicos brasileiros. Encontramos dois estudos, na Revista Motrivivência, três na Revista Movimento, três na Revista Pensar a Prática e apenas um na Revista Brasileira de Ciências do Esporte, a RBCE ${ }^{3}$.

Na Motrivivência, os estudos identificados são: Betto (2001) e Filho, Moura e Antunes (2011). Na Movimento, encontramos os estudos de Albino e Vaz (2008), Hansen e Vaz (2006) e Oliveira et al (2010). Na Pensar a Prática foram: Vaz (2006), Torri, Bassani e Vaz (2007), Santos e Damico (2009). Por fim, na RBCE, Sayão (2015).

O estudo de Betto (2001) e de Sayão (2015) retratam aspectos mais amplos sobre a política do corpo e construção do eu relacionados ao culto ao corpo. Os estudos de Hansen e Vaz (2006) e de Filho, Moura; Antunes (2011) abordam a relação entre o culto ao corpo e as academias de ginástica e de musculação. O estudo de Torri, Bassani e Vaz (2007) tratam o termo como busca da saúde e estética. Albino e Vaz (2008) se direcionam para a Revista Boa Forma para tematizar o culto ao corpo. Oliveira et al (2010) tratam da relação do culto

\footnotetext{
${ }^{3}$ Levantamento realizado no mês de setembro, do ano de 2015.
} 
ao corpo na mídia, enfocando a estética e a saúde. Por sua vez, Santos e Damico (2009), tematizam o culto ao corpo numa relação de cuidado com o corpo.

Como podemos observar no levantamento realizado, não identificamos estudos que abordam o culto ao corpo em outdoors, especificamente. Considerando-se a ausência de estudos, a presente pesquisa teve como objetivo analisar imagens de outdoors relacionadas aos cuidados com o corpo em busca de saúde, buscando-se problematizar como o ideal de corpo tem sido construído nessas imagens, com vistas a apontar implicações para a Educação Física.

Dessa forma, esse texto está organizado em três tópicos, são eles: o primeiro está intitulado de "Decisões Metodológicas", onde descrevemos a estrutura e os procedimentos realizados a fim de analisar as imagens encontradas em outdoors. O segundo tópico, “Corpos em outdoors: focalizando as aparências", apresentamos de forma explícita os outdoors elencados, acompanhados com uma análise mais profunda e a problematização quanto ao uso da imagem do corpo, o consumo, o lazer, o tempo livre, a relação com a mídia, entre outras problemáticas. No tópico "Considerações Finais", apresentamos nossas principais apreciações durante o estudo, pontos de tensão e de possíveis implicações para a Educação Física.

\section{Decisões Metodológicas}

Essa pesquisa caracteriza-se como uma pesquisa documental que analisa imagens de outdoors. Para Gil (2007), os documentos de comunicação de massa são fontes de dados para a pesquisa e contribuem para o conhecimento de diversos aspectos da sociedade.

Para a análise do material empírico optamos pela técnica da análise de conteúdo, que é "um conjunto de técnicas de análise das comunicações" (BARDIN, 2011, p. 37). De 
acordo com Bardin (2011), a análise de conteúdo deve ser constituída de três fases: a préanálise, a exploração do material e o tratamento dos resultados adquiridos e a interpretação.

Em nossa pesquisa, optamos por promover uma discussão a partir de fotografias, imagens visuais paradas. Segundo Loizos (2002, p. 137), "a imagem, com ou sem acompanhamento de som, oferece um registro restrito, mas poderoso das ações temporais e dos acontecimentos reais - concretos, materiais".

Para este autor, é possível haver informações na fotografia que nem todos estariam preparados para perceber. Neste sentido, afirma: "a manipulação da imagem visual pode ser mais sutil e oculta, mas ela é claramente ideológica" (LOIZOS, 2002, p. 140).

Neste âmbito, percebemos nas palavras de Loizos (2002, p. 138), que "‘o visual' e 'a mídia' desempenham papéis importantes na vida social, política e econômica”. Este autor não faz referência direta ao objeto de nosso estudo, entretanto, a partir dele podemos perceber que a produção de outdoors e demais formas de publicidade visual também podem estar carregados de mensagens.

Desse modo, após o período dos registros fotográficos dos outdoors, que foi de novembro, de 2014, a fevereiro, de 2015, organizamos as fotos de acordo com a data e regiões norte e sul da cidade de Natal. Em seguida, fizemos a leitura exploratória de todo o material coletado para identificarmos quais seriam analisadas nesta pesquisa.

A saber, o critério de seleção das fotos foram: ter localização em pontos movimentados na cidade, ser no máximo três registros por região (Norte e Sul) e as imagens deveriam possuir relação com a temática de cuidado com o corpo em busca de saúde. 
Assim, com as seis fotos selecionadas, construímos as fichas de conteúdo as quais determinamos uma unidade temática prévia, no sentido de identificar como os outdoors expressam a temática em questão.

Para finalizar, realizamos os tratamentos dos dados e a interpretação de acordo com o diálogo com a literatura.

\section{Corpos em Outdoors: Focalizando as Aparências}

$\mathrm{Na}$ atualidade, podemos dizer que houve um crescimento pela procura do esporte, das lutas, danças entre outras práticas, sob o discurso de serem aliadas à qualidade de vida. Neste sentido, indagamos sobre a forma de consumo dessas práticas.

Pensando sobre o tempo dedicado ao lazer e o tempo livre, Pereira (2015, p. 305), aborda o lazer como "tempo de vida e reflexão crítica ao biopoder". A autora afirma que este tempo de lazer é dedicado à vida humano-genérica, o que significa considerar as relações sociais estabelecidas, como também "o momento de desenvolvimento das potencialidades do homem” (PEREIRA, 2015, p. 305).

O estudo desta autora discute, a partir de Michel Foucault, o biopoder e as suas repercussões disciplinares e vigilantes que perpassam a existência humana. A autora considera que o poder disciplinar, presente na compreensão de biopoder, foi fundamental para o crescimento do capitalismo industrial.

No tocante ao tempo livre, a autora evidencia práticas voltadas ao consumo, à manutenção da saúde e às condições de emprego. Nas palavras de Pereira (2015, p. 328):

A fruição do tempo livre normalmente se resume em realização de viagens, práticas esportivas, cinemas, leituras e, em evidência o consumo, sendo esta a principal prática incentivada pelo biopoder, por isso a necessidade dos homens se manterem saudáveis e empregados. 
Outra forma de se pensar no tempo livre parte dos usos das mídias. No estudo de Marin (2008), a autora discute a midiatização da vida, refletindo sobre a interferência da mídia no tempo e espaço de vida dos sujeitos, enfatizando o alcance e potencial expressivo de entretenimento da televisão.

Em seu estudo, a autora considera uma perspectiva de consumo por parte da utilização deste tipo de mídia, além da possibilidade de reconfiguração dos modos de organizar e viver as práticas sociais, seus tempos e espaços. Na menção de Marin (2008, p. 2):

Com a presença das mídias na contemporaneidade toda uma racionalidade técnica se pôs a serviço para midiatizar o tempo das pessoas. Estratégias globais são apropriadas e adaptadas pelo local gerando novos produtos, que por sua vez são consumidos por diferentes contextos e indivíduos. Reconfiguram-se modos de organização e vivências das práticas sociais. Para grandes contingentes humanos, a mídia, especialmente a televisiva, passa a ocupar o lugar da praça pública, espaço comum da sociabilidade, e a interferir nas formas de compreensão e usos dos espaços e tempos sociais.

Um exemplo do potencial da mídia televisa é encontrado no estudo de Bezerra (2012), que ao analisar o quadro "Medida Certa", transmitido pela Rede Globo, demonstra que esse programa acaba veiculando padrões corporais, mais especificadamente o corpo magro, ressaltando assim uma forte influência na aparência.

Neste tipo de programa, a imagem do corpo é uma estratégia para promover o consumo de suplementos, de academias, enfim, de se vender saúde. É a imagem do corpo que é utilizada para ganhar a atenção do público, de despertar desejo nele. A visão da sociedade consumista faz com que os empresários utilizem desse tipo de recurso midiático para obter seu objetivo, o lucro. 
Soares (2008, p.73) relata uma predominância da cultura visual. Para a autora, “parece não haver dúvidas acerca do visível na definição de tudo o que concerne aos corpos no Ocidente. Parece também que essa cultura visual, predominante e potencializada pela tecnociência, alimenta essa atenção obsessiva e exagerada do corpo que se vive hoje".

Fazendo uso da mídia visual, que são os outdoors, identificamos em nossa pesquisa que, das seis fotos analisadas, cinco possuem imagens de adultos jovens e uma apresenta diversas faixas etárias. Quatro fotos apresentam apenas imagens de mulheres, uma apresenta imagem apenas de homem e outra apresenta imagens de ambos os sexos.

Dos seis outdoors escolhidos, três são de propagandas de suplementos, dois de academias de musculação e um de Pilates. Nas seis fotos, os nomes dos produtos são bem localizados, chamam atenção de quem os observa, recorrem à boa iluminação e possuem estrutura de forma retangular ou quadrada.

Quanto aos sujeitos que aparecem nessas fotos de outdoors, todos possuem postura ereta, alguns sentados ou apoiados no solo. São apresentados com boa aparência e quatro fazem uso de acessórios. Além disso, quatro fazem uso de imagens de corpos com musculatura ressaltada e definidos e duas fotos com corpos realizando algum movimento.

Sobre a expressão corporal, identificamos uma variação entre seriedade, sedução ${ }^{4} \mathrm{e}$ felicidade. Da compreensão dos corpos que aparecem, temos um corpo magro, com músculos bem definidos e imponentes (FOTO 1); dois corpos com músculos bem definidos e sedutores (FOTOS 2 e 4); um corpo magro e bem alongado (FOTO 5); outro corpo magro, feliz e com músculos bem definidos (FOTO 6) e três corpos magros e felizes (FOTO 3).

\footnotetext{
${ }^{4}$ Quanto à questão da sedução, do corpo sedutor, ou ao menos sua imagem, partimos da perspectiva de Nóbrega (2001), quando a autora aborda o corpo sexualmente disponível e associado ao hedonismo.
} 


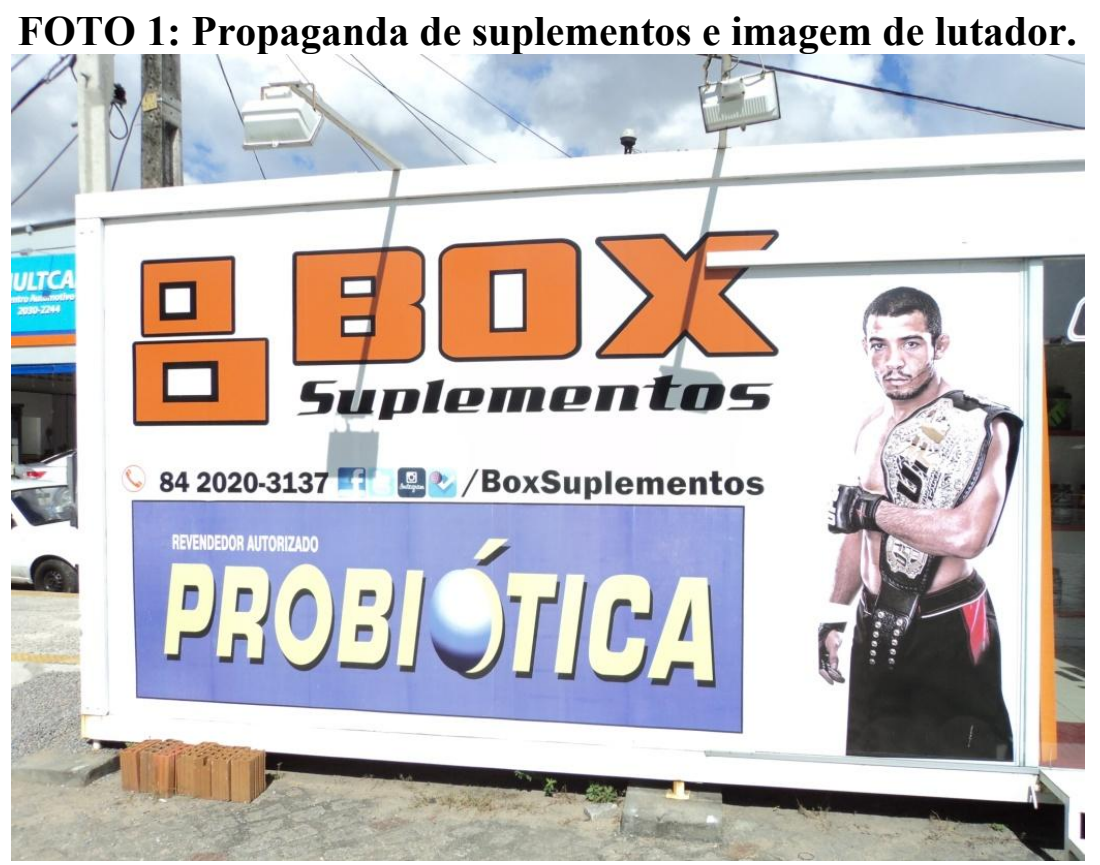

Fonte: Rivaldo Júnior

Analisando a Foto 1 identificamos a presença de um adulto jovem, gênero masculino, propaganda de suplementos com um lutador de Mixed Martial Arts (Artes Marciais Mistas), que é um esporte que vem crescendo na sociedade contemporânea. Neste outdoor, mostra-se o lutador com o cinturão de campeão de sua categoria, chamando a atenção do seu público para o desempenho que o produto pode proporcionar, ou seja, tão bom quanto o de um campeão de MMA.

Este outdoor tem seu espaço bem aproveitado, com o nome e descrição do produto bem destacado e ao centro, apenas com um homem ao lado da descrição do produto, como modelo para chamar atenção dos consumidores e futuro consumidores. Faz uso de boa luminosidade, com fundo branco. Um outdoor retangular de largura maior que a altura.

Com postura ereta, aparentando boa aparência, vestido com short e luvas característicos do esporte e com o cinturão do Ultimate Fighting Championship (entidade que promove o MMA em todo o mundo), a imagem deste profissional do ramo das lutas é 
bem destacada. Expressão facial séria e com olhar firme, imponente e acessório de campeão (cinturão). Sua imagem é utilizada para chamar atenção para os supostos benefícios do produto na propaganda e isso pode vir a corresponder ao que Leitzke, Baptista e Silva (2014, p. 190) alertam: "Figuras públicas são ótimos meios de difusão do ideário do corpo vigente".

Podemos interpretar de modo que, alcançar o corpo magro, com músculos bem definidos, sério e imponente, é algo buscado e demasiadamente desejado pelos jovens hoje em dia. Tomando estes lutadores que estão na mídia como exemplo a ser seguido, cria-se uma cultura imagética ou virtual do corpo.

Para a cultura de consumo o corpo é veículo de prazer, estando associado a imagens idealizadas de juventude, saúde, aptidão e beleza, que favorecem a expansão da indústria da moda, cosméticos, academias de ginástica e afins. A manutenção, terminologia que indica a popularização da metáfora do corpo-máquina, demanda a monitoragem do atual estado da performance corporal, envolvendo a medicina preventiva, a educação para a saúde e o fitness. Surge também a preocupação com o valor calórico dos alimentos, com os diferentes tipos de atividade física, a intensa divulgação de manuais de auto-ajuda, de dietas de todos os tipos, enfim, o disciplinamento do corpo e sua submissão à cultura do consumo. A percepção do corpo é dominada pelas imagens da cultura de consumo, refletindo na percepção da vida social e das relações humanas de um modo geral [grifo da autora] (NÓBREGA, 2001, p. 2).

A competitividade pode fazer com que algumas das pessoas que se focam nas aparências busquem corpos cada vez mais "bonitos" para o padrão imposto pela sociedade. Acabam por esquecer do bem-estar para ter um corpo aparentemente melhor que o do outro.

Nóbrega (2010), sustentando-se nos estudos de Featherstone, aborda a manutenção e a aparência como categorias que, mutuamente, se desenvolvem no âmbito do consumo. Assim, a autora define a manutenção a partir das "rotinas de adequação aos valores e 
padrões de consumo divulgados pelas próprias imagens" e a aparência como "imagens de corpo, a preocupação com o visual" (NÓBREGA, 2010, p. 23).

Observando outra interpretação do que o esporte pode promover, vivenciá-lo como algo prazeroso e buscado para a melhoria da qualidade de vida enquanto praticado.

O esporte é, assim, protagonista de um estilo de vida, de um estado de espírito e não se reduz a um conjunto de procedimentos corporais com vistas a obter resultados específicos. Ele também não é mera distração ou pedagogia virtuosa do corpo. Ancora-se na vida cotidiana e torna-se referência generalizada à existência, aos modos de cuidar de si mesmo. (SOARES, 2008, p. 80)

Partindo para outra perspectiva, a busca de uma identidade, a necessidade de ser visto na sociedade, também explica este tipo de ação: a busca por um corpo que a própria sociedade dita como sendo o ideal. Entretanto, não é somente o fato de ser de uma elite que influencia na aquisição do corpo ideal, como podemos perceber em Leitzke, Baptista e Silva (2014, p. 194):

O "consumidor" possui meios financeiros para adquiri-la. Porém, não apenas as condições financeiras influenciam na obtenção do chamado "corpo ideal". É necessário disciplina para manter as estafantes rotinas de exercícios e embelezamentos, que para a mulher, se traduzem quase como uma terceira rotina de trabalho (LEITZKE; BAPTISTA; SILVA, 2014, p. 194).

Sobre esta busca do corpo ideal, Soares (2008, p. 75) afirma: "o individualismo contemporâneo pode ser também relevado pelo imperativo do consumo, que não escapa das aparências, das práticas corporais da moda e do estilo de vida ativo, esportivo".

Os lutadores de MMA estão sendo evidenciados na mídia nesses últimos tempos, sendo tomados como ídolos e as pessoas cada vez mais procuram fazer artes marciais. No estudo de Guedes e Missaka (2015), dentre os motivos os quais levam os jovens a 
participarem de esportes, se encontram uma combinação de aspectos sociais, contextuais e pessoais.

Estes autores realizam um estudo específico com o judô brasileiro, mas podem nos auxiliar a perceber fatores determinantes para a aderência ao meio das artes marciais. A saber, Guedes e Missaka (2015) conferem ao judô, uma significação de ser um dos mais práticados esportes, por jovens brasileiros, e que possui reconhecimento mundial devido seus resultados em competições internacionais.

Investigando jovens atletas de ambos os sexos, entre a idade de 12 a 18 anos, os quais participaram da etapa final de uma competição organizada no ano de 2013, no estado do Paraná, pela Federação de Judo do Paraná, Guedes e Missaka (2015), apontam que os motivos de aderência a este tipo de prática, que levaram em conta foram: Desenvolvimento de Habilidades, Competição e Fitness, Amizade, Trabalho em Equipe, Emoção, Divertimento e Conquista/Status. Sendo que, o Desenvolvimento de habilidades, a competição e fitness foram os principais motivos para a aderência e manutenção da prática.

\section{FOTO 2: Propaganda de suplementos e modelo fitness.}

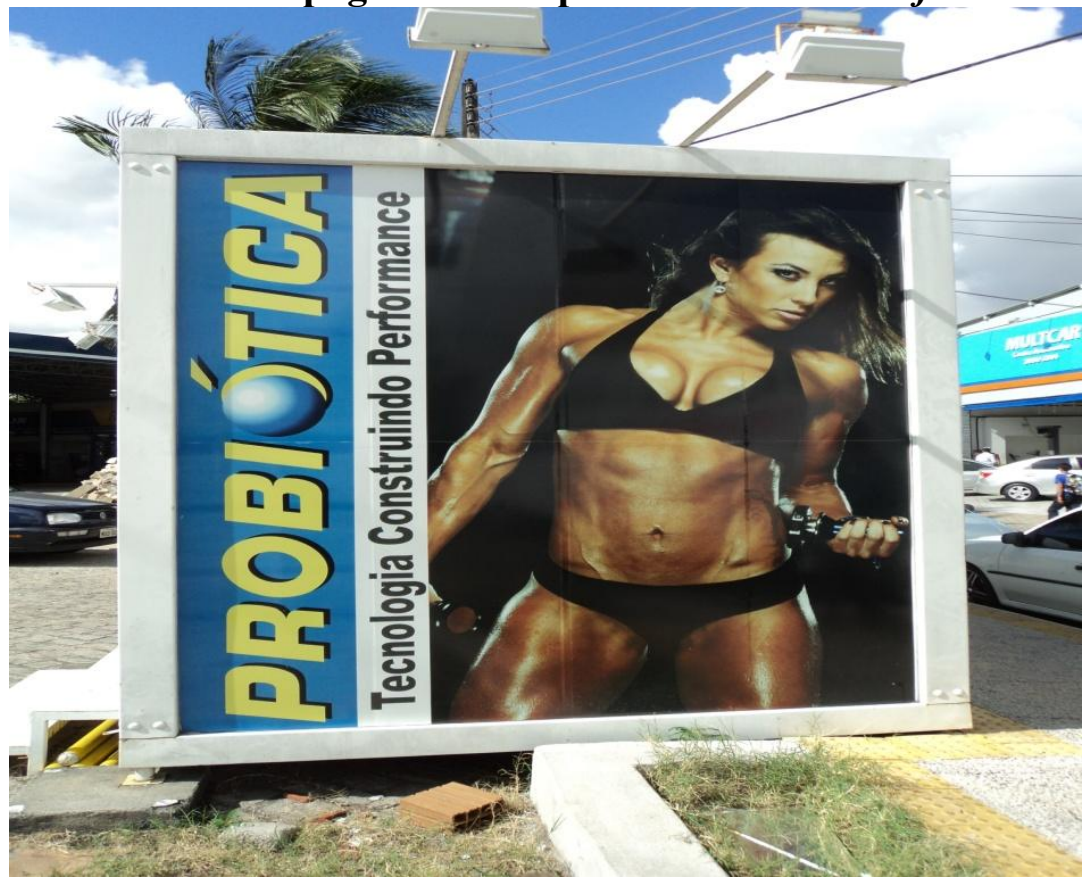

Fonte: Rivaldo Júnior 
Retomando à nossa pesquisa, quando nos direcionamos para a Foto 2, identificamos que esta imagem apresenta uma mulher, adulta, para uma propaganda de loja de suplementos. É uma modelo fitness $^{5}$ que chama a atenção para um corpo bem definido. Este modelo de corpo vem se tornando o exemplo do corpo esteticamente ideal, principalmente, no tocante ao público feminino. A localização do nome da loja encontra-se bem evidente, a modelo ocupa dois terços do outdoor, cuja estrutura é retangular com a altura maior que a largura.

Na imagem, o corpo aparece em pé, postura ereta, modelo seminua, boa aparência, acessórios de musculação (halter), mostrando o corpo definido, com expressão sedutora e dando ênfase ao abdômen. Nesta imagem vemos uma mulher posando para uma propaganda de um suplemento alimentício.

Segundo Leitzke, Baptista e Silva (2014, p. 190) “As várias representações sociais difundidas pela Indústria Cultural são primordiais neste processo de inculcação/invenção de ideais de beleza feminina, instituem um desejo, uma energia fetichizante sedutora acerca do corpo-objeto almejado".

Este tipo de propaganda que faz uso da imagem do corpo como modelo é comumente utilizado por academias e clínicas de nutrição. As autoras Moreira e Rodrigues (2014, p. 370) afirmam que "o ambiente das academias favorece a disseminação de padrões estéticos estereotipados, levan-do muitos frequentadores a desenvolver hábitos alimentares inadequados e, muitas vezes, recorrer à utilização de suplementos alimentares”.

Além disso, as autoras afirmam que a procura de suplementos aumentou, seja para homens ou mulheres. Entretanto, as autoras questionam o seu consumo em relação à saúde.

\footnotetext{
5 Entendemos, por modelo fitness, a pessoa que apresenta pouquíssima gordura corporal, musculatura trabalhada e definida e que faz uso da imagem de seu corpo como vínculo de propaganda.
} 
Neste estudo, as autoras evidenciam que a busca de suplementação tem o objetivo de aumento de massa muscular (MOREIRA; RODRIGUES, 2014).

Neste sentido, as autoras alertam: "a nutrição é uma importante ferramenta dentro da prática des-portiva e, quando bem orientada, promove a manutenção da saúde do atleta, além de favorecer o funcionamento das vias metabólicas associadas ao exercício físico" (MOREIRA; RODRIGUES, 2014, p.371).

Outra questão que se pode discutir, a partir desta mesma foto é o consumo voltado para a forma de apresentação, o que inclui vestuário, artigos de beleza, higiene e de cuidados e manipulação do corpo.

Autores como Leitzke, Baptista e Silva (2014, p. 192), consideram haver uma relação intrínseca entre saúde e beleza. No entanto, apontam para uma reificação do ser humano, sua "coisificação".

\begin{abstract}
A saúde parece-nos estar intrinsecamente ligada a um processo de "embelezamento" que viria para legitimar ideais veiculados na atualidade pela mídia e pelas relações pessoais como um todo, que permeiam e são permeados pela lógica de consumo; processos relacionados com a reificação do corpo feminino, que abarcariam grande parte da população [...]. Neste caso, a reificação é a expressão da coisificação do ser humano e de sua consciência (LEITZKE; BAPTISTA; SILVA, 2014, p. 192).
\end{abstract}

De acordo com Castro (2003), o consumo alimentar, cultural e de apresentação seriam as três mais importantes maneiras de distinguir-se.

É possível ainda encontrarmos quem não procura um profissional para orientá-las e querer obter uma melhor qualidade nos resultados deste consumo. Com relação à falta de orientação e consumo indevido, Moreira e Rodrigues (2014) discutem a preocupação com a saúde e a estética a partir do consumo de suplementos de forma equivocada: 
Ainda que a preocupação com a saúde e estética tenha aumentado notavelmente, existe muita falta de informa-ção e orientação em relação à nutrição ideal e, assim, o praticante de exercícios físicos pode vir a desenvolver e/ou manter hábitos alimentares inadequados, ou consumir erroneamente suplementos alimentares, pre-judicando o alcance de seus objetivos com a prática de exercícios físicos (MOREIRA; RODRIGUES, 2014, p. 371).

Portanto, ao nos depararmos com propagandas como estas, recordamos das palavras de Soares (2008) que, ao explorar a ideia de que conhecimentos são criados acerca do corpo, alguns têm o objetivo de educá-lo e outros para delineá-lo, regendo a forma com que este corpo se apresenta para os outros.

Se o Atlas anatômico fornece elementos centrais para derivar pedagogias do corpo e das aparências, servindo de base aos modos como o corpo deveria ser desenhado, seus segredos, entretanto, perdem terreno, e o simples jogo das aparências ganha importância. Não é mais o que está escondido debaixo da pele, mas sim o que se pode fazer com as superfícies. (SOARES, 2008. p. 72)

\section{FOTO 3: Propaganda de uma academia com pessoas se exercitando.}

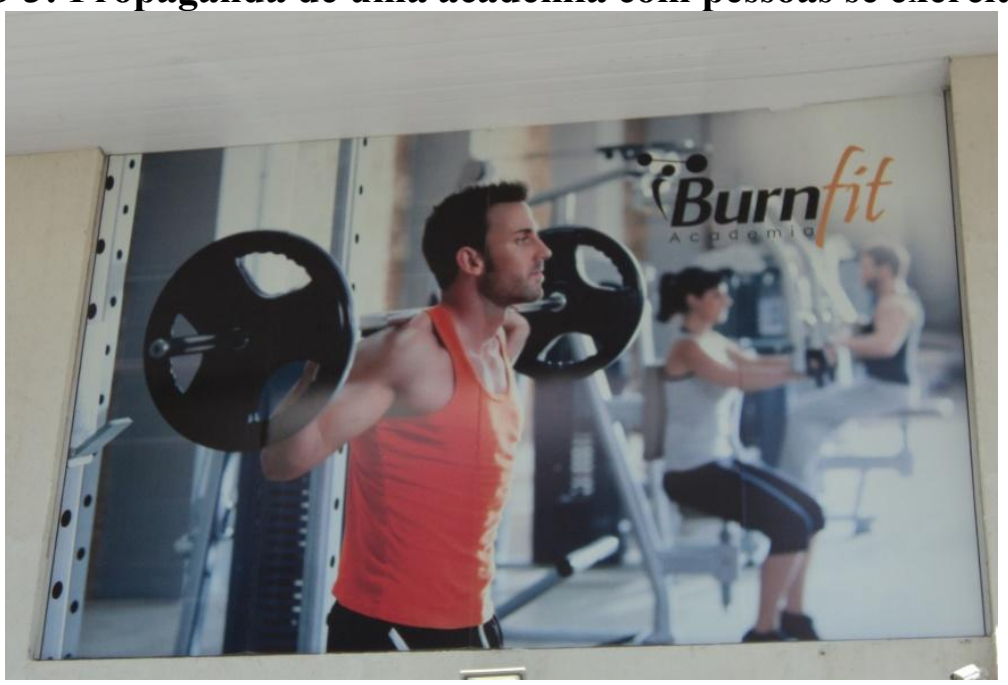

Fonte: Rivaldo Júnior

Já na Foto 3, identificamos homens e mulheres treinando em equipamentos de academia. O espaço deste outdoor mostra alguns equipamentos, pessoas treinando 
musculação, nome da academia em menor destaque, possuindo estrutura de tamanho médio e retangular, largura maior do que a altura.

$\mathrm{Na}$ Foto 3 as pessoas que aparecem no outdoor estão realizando os exercícios da musculação em pé e também sentados. Apresentam boa aparência e postura, com roupas de academia e corpos sugerindo movimento. Corpos magros e com musculatura definida. Esses corpos contribuem com a construção de um ideário de corpo.

Apesar de acreditarmos ser válido para homens também, Leitzke, Baptista e Silva (2014, p. 194) abordam este imaginário no discurso de mulheres:

O processo de aproximação entre os conceitos de beleza e saúde parecem frequentes no imaginário e discurso de mulheres na realidade atual, fruto de um processo histórico de inculcação de preceitos acerca de ideais de corpo e beleza advindos das classes dominantes e seus interesses.

Nos dias de hoje, dificilmente passamos em um bairro em Natal e não avistamos pelo menos uma academia. Neste sentido, relembramos as palavras de Melo (1998), ao considerar que o locus da academia caracteriza-se também como:

um espaço de manifestação cultural onde os indivíduos podem ter a possibilidade de conhecer, experimentar, reproduzir e transformar as diferentes modalidades (dança, ginástica, musculação, capoeira, artes marciais, tai-chi-chuan etc.) oferecidas nestes espaços (MELO, 1998, p. 131).

As propagandas das academias citadas no estudo nos passam esse tipo de mensagem. Elas não trazem para sociedade o que a prática de exercícios traz de benefícios para nós, mas sim, como o nosso corpo pode ficar com essa prática.

O estudo de Melo (1998), que investigou três academias da cidade de Campinas (SP), teve por objetivo abordar valores e significados existentes nas práticas corporais no 
contexto das academias. Objetivo este, fundamentado na premissa de que a prática da atividade física é "uma das principais formas de lazer da sociedade urbano-industrial" (MELO, 1998, p. 131).

Desse modo, a autora promove uma analogia entre o ritmo das atividades da academia e das ações cotidianas, criticando a automatização e a lógica de mercado presente na sociedade, como também propõe uma reflexão acerca de como podemos compreender a malhação.

\begin{abstract}
Pensar na possibilidade da configuração desta prática - malhação - ser uma tentativa não só de esculpir corpos, mas também de chamar a atenção para as necessidades desses em recuperar a alegria, o prazer, a qualidade de vida, a vivência do movimento e das relações sociais que se perderam, posto que se encontram paralisados pelas máquinas e solitários pela especialização do trabalho (MELO, 1998, p. 132).
\end{abstract}

Desse modo, mesmo reconhecendo a academia como espaço de manifestações culturais e propício espaço de lazer, podemos perceber a instituição de um tipo de culto na sociedade que se encontra permeado de vários discursos. Sobre este culto, Baudrillard (2008, p. 168), compreende:

o culto higiênico, dietético e terapêutico com que se rodeia, a obsessão pela juventude, elegância, virilidade/feminilidade, cuidados, regimes, práticas sacrificais que com ele se conectam, o Mito do Prazer que o circunda - tudo hoje testemunha que o corpo se tomou objecto de salvação. Substitui literalmente a alma nesta função moral e ideológica (BAUDRILLARD, 2008, p. 168).

Este culto ao corpo não mais intenciona uma busca pela sua saúde, uma vez que é permeado por uma lógica de consumo cujo propósito é distinguir-se dos demais. Sugere-se, dessa maneira, algum tipo de hierarquização social, cultural e econômica, evidenciado pela aproximação da aparência do sujeito com o ideal de corpo divulgado na sociedade. 
FOTO 4. Propaganda de suplementos com modelo fitness.

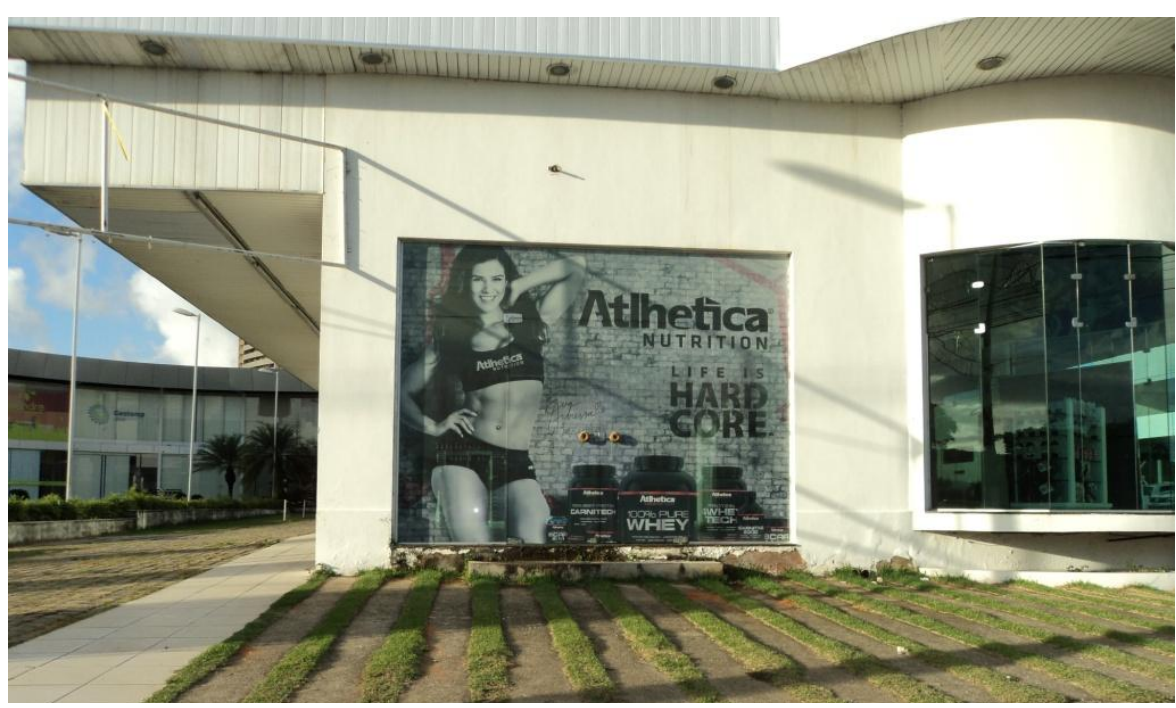

Fonte: Rivaldo Júnior

Similar à Foto 2, a imagem da Foto 4 reflete uma preocupação em se ter um corpo esteticamente belo, magro e sedutor, como ideal. O outdoor é bem localizado, com fotos dos produtos e uma modelo ao lado. Aparece o nome da loja e dos produtos de forma clara, possui boa luminosidade e a estrutura de tamanho médio e quadrado.

Com a postura ereta, boa aparência, pouca roupa, nenhum acessório, expressão feliz e corpo com musculatura definida, esta empresa utiliza da imagem do corpo da modelo para apresentar suplementos. Como se o corpo da mesma tivesse sido alcançado apenas com a utilização destes produtos.

Sabemos que há, por trás disto, outras possíveis intervenções que muitos modelos e atletas, homens e mulheres utilizam para conseguir um corpo que não somente é diferente dos demais, mas que se ressalta sob o olhar de determinados grupos sociais. Para Baudrillard (2008, p. 169), “o que pretendemos mostrar é que as estruturas actuais da 
produção/consumo induzem no sujeito uma dupla prática [...] o corpo como CAPITAL e como FEITIÇO (ou objecto de consumo)".

Neste sentido, certos modelos, homens ou mulheres são exemplos de pessoas que investem nos seus corpos para que possam utilizá-los para reconhecimento, lucro e/ou status social. Dessa maneira, configura-se o corpo como objeto de consumo e intervenção social e cultural. Com os corpos expostos nestas propagandas de suplementos, o que menos se evidencia é o produto que está sendo anunciado.

Na problemática da mulher, do corpo feminino como alvo, recurso e objeto a ser desejado (BAUDRILLARD, 2008). Na propaganda, este é utilizado como um manequim, objeto funcional, recoberto de signos em que a moda e o erótico se mesclam. O erótico entra no contexto de nossa pesquisa, pois as modelos mostram seus corpos quase que nus, com a possibilidade de ter como finalidade, despertar desejo em quem as olha. Favorecendo, supostamente, ao consumo do produto divulgado.

Sobre este movimento de construção do desejo nas mulheres e da problematização da imagem do corpo exposto, Leitzke, Baptista e Silva $(2014,186)$ afirmam:

Para a mulher, talvez este ideal de beleza seja mais fortemente veiculado e difundido, haja vista grande exposição dos corpos femininos atualmente. Essa padronização do corpo da mulher é reforçada nestes meios que corroboram para a construção da identidade - inclusive corporal feminina.

O corpo e essa ideia de beleza ajudam a vender (BAUDRILLARD, 2008), justificando o motivo da exposição do corpo em propagandas deste tipo. Assim, dentre os objetivos do corpo dito como belo e sedutor, podemos encontrar: a atração de olhares, provocar desejos e seduzir a maior quantidade de pessoas a investirem, de todas as 
maneiras, no consumo e nessa busca do corpo aparentemente semelhante ao que é evidenciado neste tipo de mídia.

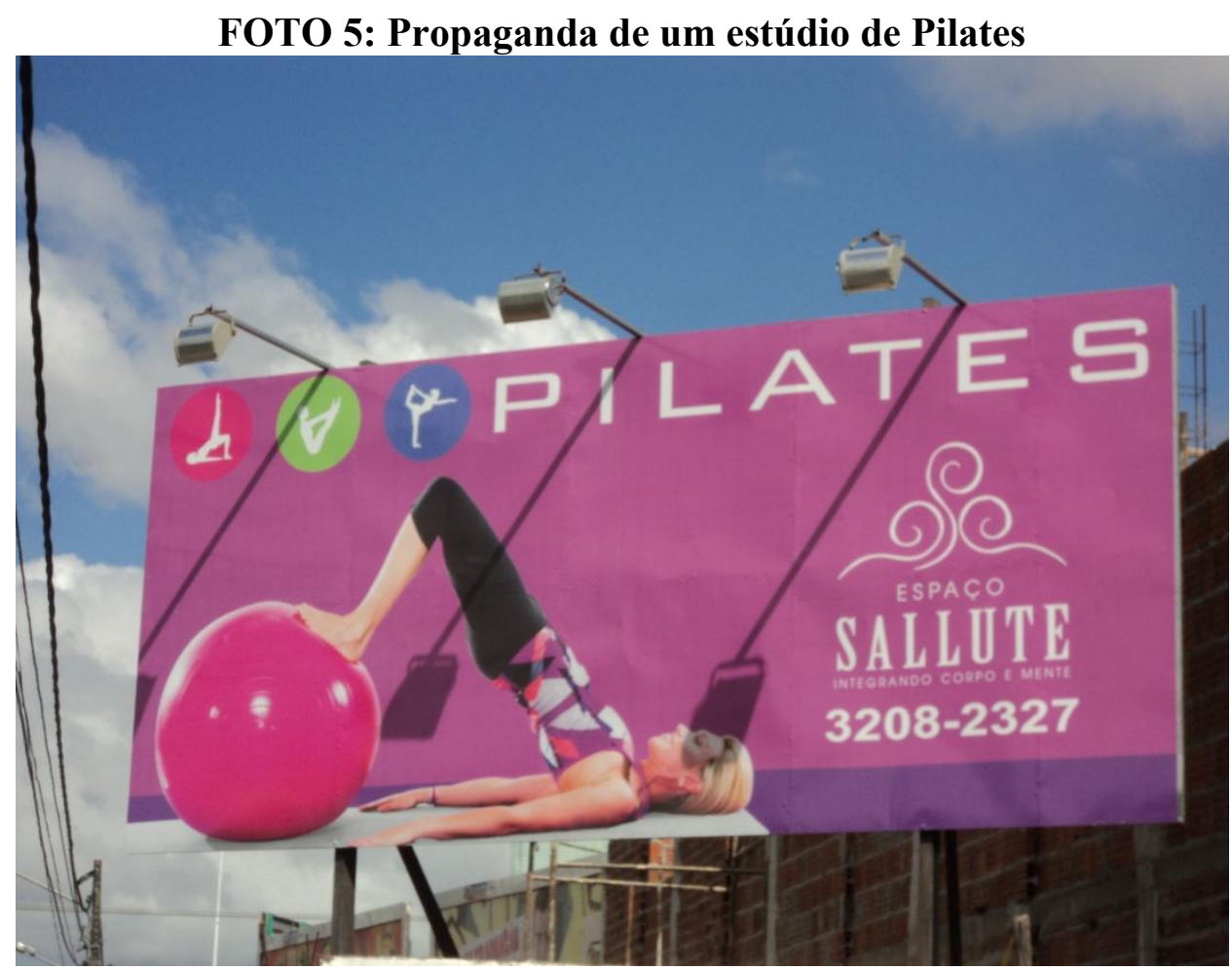

Fonte: Rivaldo Júnior

No outdoor presente na Foto 5, a pessoa que aparece é uma mulher adulta e a propaganda é de um espaço de Pilates. O nome do espaço encontra-se à margem direita e mostra-se uma mulher praticando, provavelmente, um dos exercícios executados no Pilates. O espaço ocupado pela imagem da pessoa e pelas informações textuais é distribuído de forma a enfatizar uso do corpo. Sua estrutura apresenta boa luminosidade e formato retangular.

Postura ereta enquanto realiza o exercício, boa aparência, roupa cobrindo maior parte do corpo, com a bola suíça sendo usada como acessório e expressão feliz. O outdoor 
faz uso da imagem da modelo e pode vir a sugerir um corpo feminino magro, alongado e ativo.

Segundo Pereira et al (2013), os praticantes de Pilates, o procuram em razão de melhorar, de modo geral, a saúde, o bem-estar, a qualidade de vida e seu nível de stress em uma atividade prazerosa.

Segundo os autores, dentre os motivos para a adesão das pessoas que o praticam estão: os benefícios do método e o reconhecimento do Pilates como atividade de lazer que prevalece geralmente nos fins de semana (PEREIRA et al, 2013).

No entanto, quem procura este tipo de atividade, encontra-se situado numa classe social, em termos econômicos, média ou alta, pois o custo para praticá-la não a torna acessível para todos. Neste sentido, sobre as práticas que se desenvolvem a partir da relação entre o trabalho manual e intelectual nas diferentes classes da hierarquia social, Boltanski (2004, p. 158) aponta para a possibilidade de as classes sociais mais elevadas tenderem a ter uma relação consciente com seu corpo e a treinar tanto, suas sensações físicas como expressões destas.

\begin{abstract}
À medida que se sobe na hierarquia social, que cresce o nível de instrução e que decresce correlata e progressivamente o volume de trabalho manual em favor do trabalho intelectual o sistema de regras que regem a relação dos indivíduos com o corpo também se modifica: quando sua atividade profissional é essencialmente uma atividade intelectual, não exigindo nem força nem competência físicas particulares, os agentes sociais tendem primeiramente a estabelecer uma relação consciente com o corpo e a treinar sistematicamente a percepção de suas sensações físicas e a expressão de suas sensações (BOLTANSKI, 2004, p.158).
\end{abstract}

Portanto, já podemos identificar que há uma aproximação entre o uso do corpo e as classes sociais. Boltanski (2004) também discute a relação do corpo magro e a aparência física ao se passar das classes populares às superiores. 
A valorização da "magreza" cresce quando se passa das classes populares ás classes superiores ao mesmo tempo que cresce a atenção dada à aparência física e que decresce correlativamente a valorização da força física, de maneira que dois indivíduos de mesma corpulência serão considerados como magros nas classes populares e gordos nas superiores.(BOLTANSKI, 2004, p.158)

\section{FOTO 6: Propaganda de uma academia com modelo fitness.}

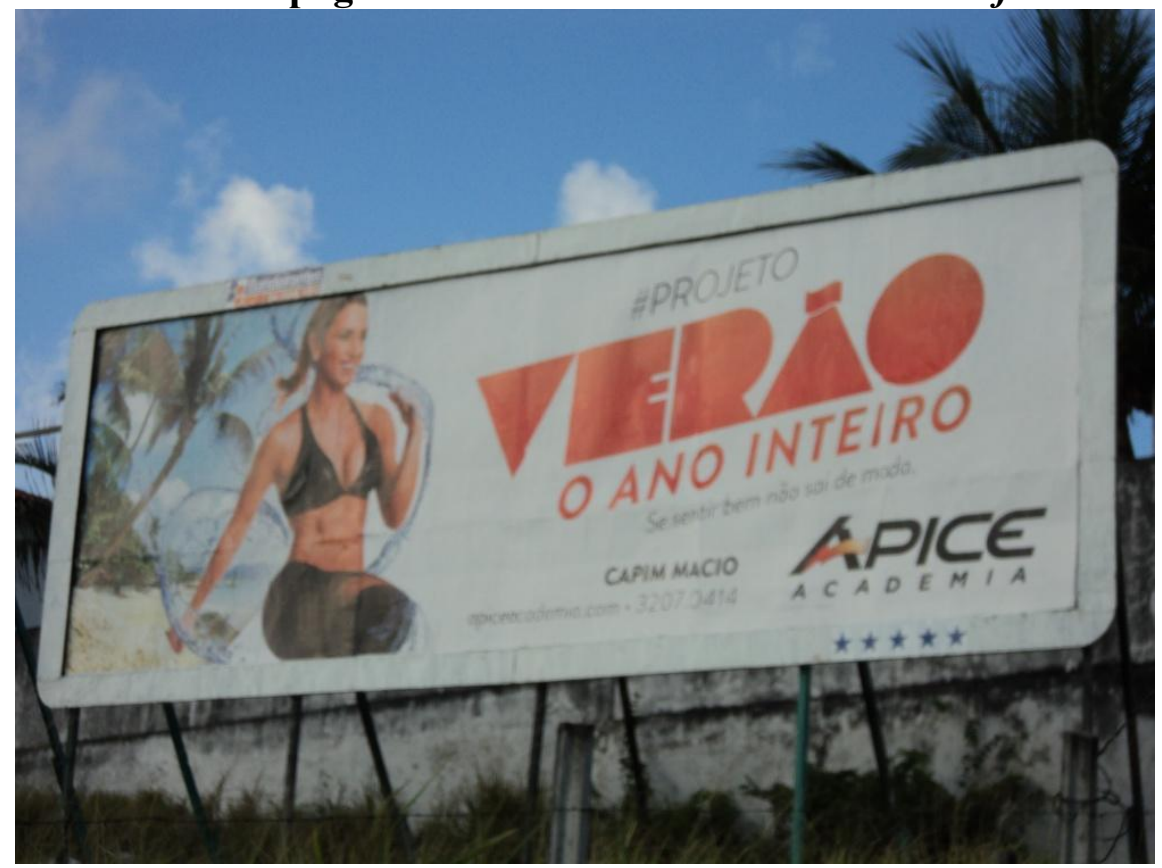

Fonte: Rivaldo Júnior

Utilizando-se também da imagem de mulheres, a Foto 6 retrata a propaganda de uma academia, com a modelo sugerindo um exercício e a exposição do corpo devido ao verão.

Sobre o outdoor, a imagem da modelo está bem destacada, chamando mais atenção que o próprio nome da academia. Sua estrutura apresenta boa iluminação, formato grande e retangular.

$\mathrm{Na}$ imagem, a modelo se encontra com a postura ereta, realizando um movimento, boa aparência, pouca roupa e nenhum acessório. Expressão de felicidade, corpo bem definido, com boa parte do busto e abdômen a mostra. 
Relacionando a imagem ao texto sobre o verão, podemos identificar um sentido de que esta estação propicia a exposição do corpo e, sugestivamente, que todos devem se preparar e praticar atividade para poderem fazê-lo.

Enfatizando o tema do prazer e de uma aparência com frescor juvenil, essa ideologia da vida e do "estar bem" alimenta as práticas consumistas que concernem diretamente ao corpo e a uma cultura corporal alheia à esfera pública, na qual se pode ler os imperativos hedonistas do: "escolha só o que te faz bem"; "neste verão desperte seus sentidos". Os pacotes de prazer que se vendem em diferentes espaços de cuidados com o corpo e a conquista de uma suposta saúde, beleza e juventude insistem sempre em jogar o jogo do bem-estar, propondo sempre conselhos adaptados à "sua" necessidade, numa conversa intima com você (SOARES, 2008, p.75).

Deste modo, o que nos propomos a problematizar é o discurso que se encontra por trás dos outdoors, mais especificadamente, os da cidade de Natal. A qualidade de vida pode até estar presente, no entanto, é mais provável que em segundo ou terceiro plano.

Assim, com essa pesquisa foi possível percebermos que podemos ter acesso a este tipo de propaganda em vários momentos do nosso dia, inclusive no tempo de lazer. Neste sentido, pensando na Educação Física também como espaço de formação para um profissional voltada para o âmbito do lazer, resgatamos as palavras de Werneck (1998) para o contexto atual, quando afirma:

Face à realidade com a qual nos deparamos atualmente, as reflexões/ações sobre a formação profissional no lazer nos colocam numa encruzilhada: enquanto para alguns as mudanças culturais provocadas no estilo de vida apresentam maiores chances para a vivência do lazer, para outros esse conteúdo é, de certa forma, limitado e ofuscado por um desejo interminável por trabalho devido, principalmente, à sua condição social na vida moderna, onde não há oportunidades dignas e nem emprego para todos (WERNECK, 1998, p. 50).

Com as palavras de Werneck (1998) finalizamos este processo de investigação. A autora considera que a mídia veicula uma ideologia que reforça um viver bem voltado ao 
consumo, um tipo de lazer que vai além da busca obsessiva do sucesso profissional, ou seja, "enquanto um produto que é comercializado na forma de shopping centers, parques temáticos, casinos, hotéis-fazenda, resorts, spas, pacotes turísticos e outras tantas atrações" (WERNECK, 1998, p. 51).

Para esta autora, o lazer é "uma possibilidade de produção de cultura, um espaço para a vivência lúdica de diferentes conteúdos que pode propiciar a leitura crítica e criativa de nosso contexto" (WERNECK, 1998, p. 49). Em razão dessas características, a autora nos propõe uma reflexão acerca do papel do lazer na sociedade em que vivemos para evitar que o utilizemos apenas como fuga de nossos problemas e frustrações.

\begin{abstract}
Nesse sentido, ao repensar a mudança do papel social do lazer em nosso contexto, não podemos ficar indiferentes a essas antigas contradições, ainda hoje muito vivas em nossa sociedade. Num contexto caracterizado pelo desemprego, pela injusta distribuição de renda, pelo analfabetismo, pela exploração de mão de obra infantil, pela pobreza, pela fome e pela miséria da maioria, fica difícil denunciar a alienação gerada pelo trabalho estruturado sob pilares da ideologia capitalista, alienação também reforçada no lazer, se este for considerado como simples diversão e entretenimento, como fuga dos problemas e como um meio de compensar as frustrações vividas cotidianamente (WERNECK, 1998, p. 50).
\end{abstract}

Portanto, pensar o lazer, na visão desta autora, é estimular a conquista de autonomia, do viver digno e a ultrapassagem de barreiras dos discursos ideológicos presentes em nosso meio, pois "a área do lazer e entretenimento vem atraindo investimentos consideráveis, multiplicando o seu público e abrindo novos horizontes de desenvolvimento para o setor” (WERNECK, 1998, p. 50).

\title{
Considerações Finais
}

Diante da problemática da sociedade consumista, a análise de outdoors, expressa saberes e práticas sobre corpo e saúde. Apresenta-se também como possibilidade para percebermos os modos de governo, usos e investimentos sobre o corpo. 
Assim, criam-se técnicas e procedimentos de se exercitar, de se alimentar, de se relacionar com os outros. Alteram-se as fisionomias, a gestualidade e outros aspectos que diretamente intervém no corpo e sua saúde.

Nos outdoors, a imagem do corpo promove um ideal que o desenha com musculatura definida, sedutor, feliz e magro, um verdadeiro corpo de campeão. Um corpo que pode expor-se em sua nudez a fim de ser tomado como exemplo e ser desejado pelos demais. Um corpo que é utilizado como objeto de consumo, produtor e produto desta lógica de aparências e propagandas. Como Nóbrega $(2001 ; 2010)$ aponta, um corpo-outdoor.

As propagandas analisadas não são acessíveis a todos. São propagandas de suplementos alimentares, academias, estúdios de pilates e clínicas de nutrição.

No tocante às imagens do corpo e a relação direta ou indireta com o produto apresentado na propaganda, identificamos que quatro possuem relação indireta e duas possuem relação direta. Propaganda de academias mostraram pessoas realizando exercícios, mas pouco se mostra sobre o que ocorre ou como é o local. As propagandas de suplementos mostram pessoas com a musculatura desenvolvida, sugerindo que foi resultado daquela suplementação, não demonstrando que existem inúmeros outros fatores para que o corpo de um atleta ou modelo fique com a aparência que observamos nas imagens.

Algumas das imagens analisadas expõem a nudez do corpo como principal meio de propaganda, ao invés do produto. Assim, o produto encontra-se em segundo plano e o corpo seminu em destaque seria, em nossa perspectiva, o real elemento do consumo.

Portanto, foi possível percebermos alguns discursos veiculados ao corpo. Em certo sentido, identificamos uma insistência no elemento da aparência como sendo mais importante do que a saúde. Segundo o material analisado e a literatura, o uso do corpo, a 
exibição do corpo seminu, corpos com músculos bem definidos, magros, são modelos de corpos a serem desejados e consumidos por essa lógica da aparência e da Indústria Cultural.

Em algumas imagens mal se percebia a imagem do produto à venda, mas o corpo sim, este é situado de modo bem chamativo. Como percebemos em Castro (2003), há um duplo aspecto no consumo: satisfazer as necessidades materiais e carregar estruturas e símbolos sociais e culturais, aspectos que consideram inseparáveis.

Entendemos que existe um culto ao corpo no sentido de uma supervalorização. Este culto garante, aos seus adeptos, o sentimento de pertencimento a um grupo social. Seguir as modas impostas pela sociedade de maneira acrítica é algo que se faz para que se sintam pertencentes da mesma, como sugere Castro (2003), ao assegurar que é através do consumo que os indivíduos vão construir seus estilos de vida na contemporaneidade.

Em relação às práticas presentes nos outdoors, às vezes, estas trazem mais problemas do que benefícios à saúde. Além de venderem uma melhoria de qualidade de vida, que não condiz com o produto ou a imagem exposta, tão pouco, evidenciam qualquer etapa do processo de desenvolvimento dos sujeitos presentes nos outdoors, nem explicitam as condições necessárias, ou mínimas, para o consumo de seus produtos.

Portanto, é imprescindível que os profissionais de Educação Física reflitam sobre a proliferação do culto ao corpo em diversos cenários educativos em nossa sociedade, inclusive nos outdoors, e tenham um olhar crítico sobre esse fenômeno ao invés de reforçálo.

Nesse sentido, reconhecemos que esses ideais de corpo são fenômenos culturais que são constantemente reconstruídos. Portanto, nesta pesquisa apontamos a necessidade de ampliarmos nosso olhar sobre o corpo e a saúde em relação ao consumo e ao lazer. 
Por fim, reconhecemos também a importância de mantermos estas questões entre corpo, saúde, lazer e consumo sempre em movimento, pois seria uma de nossas funções, como profissionais da Educação Física, problematizarmos essa busca desenfreada pelo corpo ideal e as práticas sociais e ideologias que apenas a fortalecem.

\section{REFERÊNCIAS}

ALBINO, B. S; VAZ, A. F. O corpo e as técnicas para o embelezamento feminino: esquemas da indústria cultural na Revista Boa Forma. Movimento, v.14, n.1, p. 199-223, jan./abril, 2008.

BARDIN, L. Análise de conteúdo. São Paulo: Edições 70, 2011.

BAUDRILLARD, J. A sociedade de consumo. 2. Portugal: Edições 70. 2008.

BETTO, F. Políticas do corpo. Motrivivência, v. 11, n. 15, p. 1-5, .Agosto/2001.

BEZERRA, H. P. O. Corpo e Saúde: reflexões sobre o quadro "Medida Certa". (Dissertação) Mestrado em Educação Física. Universidade Federal do Rio Grande do Norte, Natal, 2012.

BOLTANSKI, L. As classes sociais e o corpo. Rio de janeiro: Graal, 2004.

BRUHNS, H. T. A crise do lazer moderno e concepções de corpo. Licere, Belo Horizonte, v. 12, n. 4, p. 1-18, dez/2009.

CASTRO, A. L. Culto ao corpo e sociedade: mídia, estilo de vida e cultura de consumo. São Paulo: Annablume; FAPESP, 2003.

FILHO, J. C. de M. G; MOURA, D. L; ANTUNES, M. M. Quando a beleza põe a mesa: uma análise das condições de trabalho do profissional de educação física em megaacademias. Motrivivência, Santa Catarina, v. 23, n. 36, p. 197-213, Junho/2011.

GIL, A. C. Métodos e técnicas de pesquisa social. 5. Ed. São Paulo: Atlas, 2007.

GUEDES, D. P; MISSAKA, M. S. Sport participation motives of young Brazilian judo athletes. Motriz, Rio Claro, v.21 n. 1, p. 84-91, Jan./Mar., 2015.

HANSEN, R.; VAZ, A. F. "Sarados" e "gostosas" entre alguns outros: aspectos da educação de corpos masculinos e femininos em academias de ginástica e musculação. Movimento, Porto Alegre, v.12, n. 1, p.133-152, jan./abril, 2006.

LACERDA, L. L.L. de; ISAYAMA, H. F. Lazer e marketing: considerações sobre mercado e consumo. Licere, Belo Horizonte, v.12, n. 3, p. 1-22, setembro/2009. 
LEITZKE, A. T. S.; BAPTISTA, T. J. R.; SILVA, A. M. Relações entre beleza e saúde feminina: um olhar a partir da perspectiva de professoras de Educação Física. Motrivivência, v. 26, n. 43, p. 183-197, dezembro, 2014.

LOIZOS, P. Vídeo, filme e fotografias como documentos de pesquisa. In: BAUER, M. W; GASKELL, G. Pesquisa qualitativa com texto, imagem e som: um manual prático. Petrópolis: Vozes, 2002.

MARIN, E. C. A midiatização da vida. Licere, v. 11, n. 1, p. 1-27, abr/2008.

MENDES, M. I. B. de S. Do ideal de robustez ao ideal de magreza: Educação Física, saúde e estética. Movimento, Porto Alegre, v. 15, n. 04, p. 175-191, outubro/dezembro, 2009.

MELO, C. K. A malhação do lazer... ou seria malhação no lazer? Uma análise sobre a multidimensionalidade da cultura expressa através dos corpos nas academias. Licere, v. 1, n. 1, p. 131-132, 1998.

MOREIRA, F. P; RODRIGUES, K. L. Conhecimento nutricional e suplementação alimentar por praticantes de exercícios físicos. Revista Brasileira de Medicina do Esporte, v. 20, n. 5, p. 370-373, set/out. 2004.

NÓBREGA, P. T. Agenciamento do corpo na sociedade contemporâneo: uma abordagem estética do conhecimento da Educação Física. Motrivivência, v. 12, n. 16, p.1-11, março/2001.

Uma fenomenologia do corpo. São Paulo: Editora Libraria da Física, 2010. (Coleção contextos da ciência).

OLIVEIRA, A. P. et al. de. Culto ao corpo e exposição de produtos na mídia especializada em estética e saúde. Movimento, v. 16, n. 01, p. 31-51, jan./março de 2010.

PEREIRA, E. C. et al. A aderência de pessoas no Pilates solo. Fisioter. Bras. v. 14, n. 1, p. 49-55, jan/fev., 2013.

PEREIRA, M. A. S. O capital humano no contexto do biopoder: o tempo livre vigiado e consumido. Licere, v. 18, n. 3, p. 305-330, set/2015.

SANTOS, F. da C; DAMICO, J. G. S. O MAL - ESTAR NA VELHICE COMO CONSTRUÇÃO SOCIAL. Pensar a Prática, Goiás, v.12, n.1, p. 1-9, jan./abril, 2009.

SAYÃO, M. N. O culto (in)quieto do eu eficaz. Revista Brasileira de Ciência do Esporte, Rio de Janeiro, v.31, n.1, p. 35-41, janeiro, 2015.

SOARES, C. L. A educação do corpo e o trabalho das aparências: o predomínio do olhar. In: ALBUQUERQE JÚNIOR, D. M.; VEIGA NETO, A; SOUZA FILHO, A. Cartografias de Foucault. Belo Horizonte: Autêntica, 2008. p.69-82.

Corpo, conhecimento e educação. In: SOARES, C. L. (Org.). Corpo e história. São Paulo: Autores Associados, 2001, p. 109 - 129. 
TORRI, J.; BASSANI, J. J; VAZ, A. F. DOR E TECNIFICAÇÃO NO CONTEMPORÂNeO CUlto AO CORPO. Pensar a Prática, v.12, n.2, p. 261-273, julho/dez., 2007.

VAZ, A. F. Reflexões de passagem sobre o lazer: notas sobre a pedagogia da indústria cultura. Licere, v. 9, n. 1, p. 13-26, 2006.

WERNECK, C. L. G. Lazer e formação profissional na sociedade atual: repensando os limites os horizontes e os desafios para a área. Licere, v. 1, n. 1, p. 47-65, 1998.

\section{Endereço dos Autores:}

Iasmim de Pontes Araújo

Universidade Federal do Rio Grande do Norte - UFRN

Departamento de Educação Física

Programa de Pós-Graduação em Educação Física

Av. Senador Salgado Filho, 3000,

Campus Universitário - Lagoa Nova

Natal - RN - 59.072-970

Endereço Eletrônico: iasmimparaujo@gmail.com

Marcel Alves Franco

Universidade Federal do Rio Grande do Norte - UFRN

Departamento de Educação Física

Programa de Pós-Graduação em Educação Física

Av. Senador Salgado Filho, 3000,

Campus Universitário - Lagoa Nova

Natal - RN - 59.072-970

Endereço Eletrônico: macfranco1@gmail.com

Maria Isabel Brandão de Souza Mendes

Universidade Federal do Rio Grande do Norte - UFRN

Departamento de Educação Física

Programa de Pós-Graduação em Educação Física

Av. Senador Salgado Filho, 3000,

Campus Universitário - Lagoa Nova

Natal - RN - 59.072-970

Endereço Eletrônico: isabelbsm1@gmail.com 